\title{
CORRESPONDENCE
}

\section{Peer reviews: in praise of referees}

Unlike Hidde Ploegh, I am grateful to reviewers who suggest lateral experiments (Nature 472, 391; 2011). Good science depends on reproducible results, and the reviewers are often just calling on authors to replicate their results by different means.

Ploegh is critical of the cost and extra time needed to do more experiments, but what about the cost in wasted time when published results cannot be replicated? In my experience, the lateral experiments are usually better than those the authors planned to do next anyway. They often strengthen the original results and lead to useful discoveries.

Reviewers are doing authors a great favour in suggesting specific, focused experiments; they subsequently spend (unpaid) time re-reviewing the paper. Rather than criticism, they deserve a resounding thanks. Eric L. Altschuler New Jersey Medical School, New Jersey, USA. altschel@umdnj.edu

\section{Peer reviews: make them public}

Making peer reviewers' comments public - not necessarily signed - would alleviate most of the problems outlined by Hidde Ploegh

(Nature 472, 391; 2011).

Readers of the comments would then be able to judge, for example, whether reviewer requests for additional experiments were reasonable. Such a public-review policy would help editors and add a new dimension to a journal's reputation, particularly if others in the field publicly shared their own relevant observations.

In conventional peer review, especially at top-tier journals, much of the reviewing effort goes into manuscripts that are ultimately rejected, meaning that the scientific community has no access to these communications. Under a public system, these records could prevent reinventions of the wheel and help educate newcomers to the field or to peer reviewing.

Publicly available reviews, including those of rejected manuscripts, would also provide an incentive for authors to submit their manuscript only when it is ready - helping to lower rejection rates and aiding the search for suitable reviewers (see go.nature.com/qamrfc). Daniel Mietchen EvoMRI Consulting, Jena, Germany. daniel.mietchen@evomri.net

\section{Cooperation is key to Asian hydropower}

Environmentalists won a reprieve last month against construction of the Xayaburi dam on the lower Mekong River in Laos (Nature doi:10.1038/news.2011.220). But it is the Laos government that will have the final say.

China is leading this

hydropower boom in southeast Asia, and aims to increase its hydropower from 200 to 380 gigawatts by 2020 . Dams are planned or completed at sites along other international rivers, including 13 on the Salween or Nujiang, which is protected by UNESCO (United Nations Educational, Scientific and Cultural Organization), and 20 along the Brahmaputra - all in rare and fragile environments.

In 2004, Chinese Premier Wen Jiabao halted the development of dams along the Salween. But the order was lifted after the National Development and Reform Commission called last year for dam building to proceed, prompted by soaring power demands and the energy and water conservation targets of
China’s latest five-year plan.

This wave of development in hydropower and its effect on water resources is likely to intensify water-related disputes among neighbouring riparian countries. To assess properly the impact of building hydropower dams, transparent policies and multinational cooperation are crucial.

Lishan Ran, X. X. Lu National University of Singapore, Singapore. geoluxx@nus.edu.sg

\section{Seeking out Earth's warning signals}

I disagree with Robert Geller's hard-line stance against earthquake prediction (Nature 472, 407-409; 2011). Although early warning signs are diverse, fleeting and often subtle, they can also be surprisingly strong, even for moderate earthquakes (see, for example, T. Bleier et al. Nat. Hazards Earth Syst. Sci. 9, 585-603; 2009).

More than 100 years of seismology have led to an advanced understanding of the tectonic forces that cause Earth's plates to move, slide past each other and collide. But when it comes to earthquake prediction, the seismological approach has always been to try to understand how past events happened and to develop probability models for 'predicting' when the next ones might occur. This analysis has built-in statistical uncertainties that are of the order of years, decades, even centuries - and there is no way around it.

Any good seismologist will recognize the limitations of earthquake prediction.

But the study of earthquakes should include the tracking down and investigation of all the different signals that Earth produces before a catastrophic rupture. If seismologists can't do it alone, can't we do it collectively across disciplines?

Friedemann Freund NASA Ames Research Center, SETI Institute and San Jose State University, California, USA. friedemann.t.freund@nasa.gov

\section{Can Facebook influence funding?}

I would like to make it clear that I played no part in instigating a Facebook uprising over my research (Nature 472, 410-411; 2011).

I am not an activist but a scientist who has published 27 peer-reviewed studies of chronic cerebrospinal venous insufficiency (CCSVI) and its relationship to multiple sclerosis in 18 interdisciplinary journals.

This research was funded by the Italian government and banking foundations, and grants were peer-reviewed by scientific committees under the usual rules.

I do not believe that Facebook can influence the diversion of funds to change research priorities or the judgement of the scientific community.

CCSVI is a pathological condition first described in the literature two years ago. A Google Scholar search reveals that CCSVI has been cited more than 2,000 times in published scientific papers. Evidently, CCSVI is a hot topic - it is interesting precisely because it is controversial.

Paolo Zamboni University of Ferrara, Italy.zambo@unife.it Competing financial interests declared (see http://dx.doi.org/ 10.1038/473452e).

\section{CONTRIBUTIONS}

Correspondence may be submitted to correspondence@nature. com after consulting the author guidelines at http:// go.nature.com/cmchno. 